\title{
ПОДОХОДНОЕ НАЛОГООБЛОЖЕНИЕ ФИЗИЧЕСКИХ ЛИЦ: ТЕНДЕНЦИИ ПРИНУЖДЕНИЯ И СТИМУЛИРОВАНИЯ
}

\begin{abstract}
Ю.К. Цареградская*
Анализируется подоходное налогообложение физических лиц с учетом выполняемых налогами функций. Сделан вывод о том, что государство использует в процессе налогообложения взаимосвязанно и принуждение, и стимулирование.
\end{abstract}

Ключевые слова: подоходный налог, Республика Беларусь, Россия, стимулирование, принуждение.

JEL-классификация: Н24, К34.

DOI: $10.46782 / 1818-4510-2021-2-63-69$

Материал поступил 19.04.2021 2.

Налоги традиционно рассматриваются как один из старейших атрибутов государства, позволяющий ему функционировать. Периодически происходит трансформация налогообложения, направленная на эффективную реализацию принципов доступности, экономии и справедливости. В условиях кризисных явлений вопросы налогообложения становятся наиболее острыми для обсуждения в силу того, что, с одной стороны, государство нуждается в привлечении большего количества денежных средств за счет налоговых поступлений, а с другой - увеличение налоговой нагрузки может негативно отразиться на поведении налогоплательщиков, которые начнут уклоняться от выполнения налоговой обязанности. В связи с этим государство обычно просчитывает, какие меры стимулирования окажутся эффективными в противовес неправомерному поведению налогоплательщиков, чтобы принудить их к уплате налогов. Значимость подобного исследования заключается в том, чтобы на основе научных взглядов разных специалистов проанализировать существующие механизмы налогового принуждения и стимулирования в целях возможного использования лучших практик данных отношений в национальной налоговой политике.

\section{Принуждение в сфере налогообложения}

Считается, что принуждение в налоговой сфере нацелено на процессы демократизации и развития гражданского общества в целом, а также на обеспечение финансовой устойчивости государства. По мнению О.Н. Князевой, А.Н. Шагланова (2014. С. 102), в последнее время возросло количество лиц, не заинтересованных в добросовестном исполнении ими налоговой обязанности, в результате чего государство недополучает большие суммы доходов бюджета.

Говоря о налоговом принуждении, следует иметь ввиду, что можно его рассматривать как в широком смысле, так и в узком. Широкое толкование характеризуется наличием позитивной налоговой ответственности, которая сводится к выполнению налогоплательщиком своей обязанности по уплате установленных налогов и сборов. В отечественной практике позитивной форме юридической ответственности уделяется не так много внимания, поскольку это считается данностью. В зарубежной литературе и прак-

* Цареградская Юлия Константиновна (ukmsal@mail.ru), доктор юридических наук, доцент, Московский государственный институт международных отношений (г. Москва, Россия). 
тике налоговых отношений, особенно в США, уделяется больше внимания данному вопросу. В частности, налоговые органы США стремятся повысить уровень добровольного соблюдения налогового законодательства всеми участниками налоговых правоотношений, с этой целью предусмотрены гражданско-правовые санкции ${ }^{1}$. Без них общество не стало бы соблюдать налоговое законодательство (Madison, 2016. Р. 392). Таким образом, получается, что их применение является фактором, влияющим на поведение участников налоговых правоотношений.

В узком понимании слова налоговое принуждение можно рассматривать как систему определенных мер предупредительного и восстановительного характера, применяемых к участникам налоговых правоотношений для соблюдения законности в сфере налогообложения.

Следует отметить специфические признаки мер налогового принуждения:

- всеобщность, т. е. распространение на всех участников налоговых правоотношений;

- законность, поскольку поведение субъектов осуществляется в рамках соблюдения установленных правил уплаты налогов и сборов;

- санкционный характер, предусматривающий применение различных мер воздействия (финансовых, административных и уголовных);

- внесудебный характер, что обусловлено применением мер налогового принуждения специальными органами государственной власти (налоговыми органами);

- государственно-властный характер, проявляется в реализации мер принуждения не в отношении подчиненных субъектов;

- целевой характер, заключающийся в том, что происходит понуждение к исполнению всеми участниками налоговых правоотношений установленных обязанностей в сфере налогообложения;

- процессуальный порядок, который связан с применением мер принуждения в соответствии с установленным законодательством.

Таким образом, правовое принуждение - это воздействие государства на со-

\footnotetext{
${ }^{1}$ Internal Revenue Manuals. URL: https://www.irs.gov/irm
}

знание и поведение участников налоговых правоотношений путем создания норм, устанавливающих правила уплаты налогов и сборов, а также применения к ним принудительных мер в случаях нарушения законодательства.

Одной из основных особенностей налоговых отношений является изъятие части стоимости материальных благ, принадлежащих налогоплательщикам, для финансового обеспечения функционирования государства. Принудительный характер изъятия доходов вызывает желание у налогоплательщиков уклоняться от уплаты налогов и сборов. По мнению М.В. Карасевой (2003. С. 32), данная ситуация свидетельствует о конфликтности налоговых отношений относительно собственности. Принудительное отчуждение вызывает протест, поскольку любой хозяйствующий субъект не заинтересован в уплате каких-либо платежей в бюджет, ведь это уменьшает его благосостояние.

Однако в контексте налогового принуждения следует иметь ввиду всех участников налоговых правоотношений. Для должностных лиц налоговых органов предусматриваются меры ответственности за невыполнение своих обязанностей, связанных с соблюдением прав и законных интересов налогоплательщиков, а для лиц с девиантным поведением есть соответствующие меры за нарушения в сфере налогообложения (Кобзарь-Фролова, 2010. С. 59).

Злоупотребления налогоплательщиков в налоговых правоотношениях порождают проблему применения налогового стимулирования, в частности выраженного правом на оптимизацию налогообложения, которое, по мнению П.В. Сунцевой (2010. С. 91), может быть не реализовано из-за злоупотребления налоговыми органами своими правами и полномочиями.

Исходя из вышесказанного, а также анализа положений налогового законодательства, можно сделать вывод о том, что большинство налоговых норм нацелены на предотвращение уклонения от уплаты налогов. Это позволяет говорить о превалировании охранительной функции налогового права, что, в принципе, является обоснованным, и многие авторы сходятся в этом мнении (Быков, 2014. С. 92). 


\section{Стимулирование участников налоговых отношений}

Налоговая политика любого государства не может строиться только на принуждении, поскольку это будет неэффективно для функционирования государства. В связи с этим и появляются стимулирующие правомерное поведение механизмы.

Наиболее распространенными стимулирующими мерами являются налоговые льготы, преимущественно выражающиеся в разных способах снижения налогового бремени. В связи с тем, что налоговые льготы выгодны для налогоплательщиков, но для государства могут привести к негативным последствиям (снижение доходов бюджета, чрезмерное налоговое планирование и пр.), следует соблюдать определенный баланс в их применении. Если налоговые льготы стимулируют привлечение инвестиций, способствующих экономическому росту в государстве, они используются достаточно активно. При росте издержек от их применения государство начинает уменьшать их количество.

Роль стимулирования в налогообложении активно обсуждается в научной литературе при характеристике функций, которые выполняют налоги. Традиционно выделяют следующие: фискальную, распределительную, регулирующую, контрольную. Однако встречаются и вариации, объединяющие несколько функций в одну или разделяющие одну функцию на несколько (Митрофанова, 2013; Сокул, 2010). Достаточно часто стимулирующую функцию рассматривают в контексте регулирующей функции. В частности, А.В. Брызгалин ${ }^{2}$ указывает на стимулирующую подфункцию регулирования налогообложения, которая способствует развитию экономических процессов посредством налоговых льгот и освобождений. Е.Ю. Жидкова ${ }^{3}$ выделяет отдельно стимулирующую функцию, характеризуя ее как систему налоговых льгот и налоговых преференций. По ее мнению, государство таким образом вынуждает субъектов налоговых правоотношений дей-

\footnotetext{
2 Брызгалин А.В. 1998. Налоги и налоговое право: учебное пособие. Москва: Аналитика-Пресс С. 205.

${ }^{3}$ Жидкова Е.Ю. 2009. Налоги и налогообложение: учебное пособие. Москва: Эксмо. С. 221.
}

ствовать в определенном направлении, выгодном государству. И.А. Митрофанова (2013. С. 40) считает стимулирующую функцию наиболее труднореализуемой, поскольку она связана с экономическими интересами налогоплательщиков. В свою очередь, П. Сокул (2010. С. 116) указывает на то, что стимулирующая функция, обеспечивая использование налоговых инструментов, оказывает влияние на деятельность налогоплательщиков.

На этих примерах видно, что стимулирующая функция сводится преимущественно к применению налоговых льгот в отношении субъектов налоговых правоотношений.

Наиболее распространенными формами налоговых льгот, предоставляемыми налогоплательщикам, являются следующие: освобождение от уплаты налога;

установление пониженной ставки налога;

сокращение объектов налогообложения;

уменьшение налоговой базы;

уменьшение налога, подлежащего уплате в бюджет (Белякова, Моденов, 2019. C. 135).

Для физических лиц налоговые льготы в рамках подоходного налогообложения выражаются налоговыми вычетами: социальными, стандартными, имущественными, инвестиционными, профессиональными.

В соответствии с Налоговым кодексом РФ, налогоплательщики, имеющие детей, имеют право на стандартные налоговые вычеты. В целях повышения доступности образования и здравоохранения при получении образования и оказании услуг, связанных с лечением гражданина, предоставляется возможность реализовать право на получение социального налогового вычета. При приобретении жилья физическое лицо имеет право на имущественный налоговый вычет.

Использование налоговых льгот в качестве стимулирования должно быть эффективным, в связи с этим необходимо проводить анализ предоставляемых льгот. В случае их неэффективности следует подумать об их отмене или замене более эффективными налоговыми инструментами. 


\section{Налогообложение в России и Беларуси: налоговое принуждение и стимулирование}

Учитывая кризисные явления на фоне пандемии, вызванной коронавирусной инфекцией, государства начинают вносить изменения в налоговое законодательство, которые могут быть связаны с увеличением налогового бремени и стимулированием налогообложения. В настоящее время, рассматривая налоговую политику ряда стран, можем найти подтверждение данного тезиса на примере практики налоговых отношений в России и Беларуси.

Для России характерны и увеличение налоговой нагрузки, и меры по стимулированию налогообложения. Так, с 2021 г. изменения, увеличивающие налоговую нагрузку, затрагивают налогообложение доходов физических лиц по следующим направлениям:

- облагаются налогом по ставке 13\% вклады в банке, если сумма денежных средств превышает 1 млн руб. При наличии нескольких вкладов в разных банках в сумме, превышающей 1 млн руб., данная сумма должна облагаться налогом за вычетом необлагаемого дохода с 1 млн руб. Следует иметь ввиду, что банки не будут удерживать сумму налога и перечислять ее в налоговую инспекцию, так как обязанность по уплате возлагается на вкладчиков после получения уведомления с конкретной суммой налога, которая рассчитывается исходя из данных от кредитных организаций о процентах, выплаченных физическим лицам по вкладам. Средства, полученные по указанной ставке, будут целевыми, так как позволят профинансировать социальные выплаты семьям с детьми и безработным. Не попадают под объект налогообложения в данном случае: а) доходы по рублевым счетам со ставкой ниже $1 \%$ (текущие, зарплатные счета и пр.); б) процентные доходы по счетам эскроу;

- вводится повышенная ставка НДФЛ в размере $15 \%$ для граждан, чей доход составляет от 5 млн руб. в год 4 . Повышенная ставка НДФЛ будет применяться к регулярным доходам граждан (в частности, заработная плата, дивиденды, купонные доходы по

${ }^{4}$ Налоговый кодекс Российской Федерации (часть вторая) от 05.08.2000 г. № 117-ФЗ. Собрание законодательства РФ. 2000. № 32. Ст. 3340. облигациям и ценным бумагам; доходы от предпринимательской деятельности; доходы из-за рубежа и пр.). Нерегулярные доходы, например от продажи имущества, не попадают под объект налогообложения по данной ставке. Средства, полученные по такой процентной ставке НДФЛ, будут целевыми доходами и поступят в региональные бюджеты для финансирования лечения детей от редких и тяжелых болезней. Вопрос о прогрессивной шкале налогообложения всегда является достаточно дискуссионным в практике его применения, но в условиях кризиса он оправдан. В частности, в сентябре 2020 г. 83 миллионера из Нидерландов, Дании, Великобритании, Германии и США подписали петицию, обращенную к органам власти, о повышении так называемого «налога на богатых» с целью оказания помощи населению в связи с пандемией (Клюев, 2020. С. 47). В этих странах социальное самосознание благоприятствует изменению налоговой политики в целях финансирования малообеспеченных. В условиях отечественного менталитета подобные меры могут быть введены в рамках принуждения по инициативе государства;

- вводится обложение доходов любых облигаций по ставке $13 \%$ для резидентов и $30 \%$ для нерезидентов, независимо от суммы инвестиций. Налоги будут удерживаться налоговыми агентами, т. е. брокерами. Исключением является неуплата налога резидентами России, если их облигации находятся на индивидуальном инвестиционном счете.

Данные решения об увеличении налоговой нагрузки были приняты в связи с уменьшением бюджетных доходов, вызванных пандемией.

Наряду с рассматриваемыми изменениями налогового законодательства России в текущем периоде, имеются преобразования и стимулирующего характера. В частности, расширился вычет по НДФЛ, связанный с лечением, в связи с чем, начиная с 2021 г., перечень медицинских услуг расширился за счет паллиативой помощи и оказания услуг по медицинской эвакуации. Дорогостоящие услуги были дополнены следующими:

оказываемыми в рамках паллиатива; 
по ортопедическому лечению врожденных или приобретенных зубных дефектов; с использованием репродуктивных технологий.

Чтобы воспользоваться данным вычетом, необходимо собирать все документы, подтверждающие расходы на лечение в течение 1 календарного года. Налогоплательщик может оформить вычет за супруга, детей до 18 лет, а также родителей ${ }^{5}$.

Если обратиться к налоговому законодательству Республики Беларусь, можем увидеть значительные изменения в подоходном налогообложении, связанные, в большей степени, с его стимулированием.

Основные изменения налогового законодательства сводятся к следующим направлениям:

увеличение размеров вычетов на детей и иждивенцев;

увеличение сумм стандартных налоговых вычетов социально не защищенным категориям налогоплательщиков (например, инвалидам разных категорий, лицам, осуществлявшим интернациональный долг во время существования СССР, ликвидаторам техногенных катастроф и пр.);

индексация видов доходов, освобожденных от подоходного налога, с физических лиц;

расширение перечня доходов, освобождаемых от данного налогообложения.

В частности, Налоговый кодекс Республики Беларусь предусматривает обширный список видов доходов, которые выводятся из-под обложения подоходным налогом. С 2021 г. данный список расширился следующими показателями:

суммы материальной помощи, предоставляемые профсоюзом членам семьи умершего работника, который состоял в профсоюзной организации;

суммы, получаемые от профсоюзов, которые не являются вознаграждением за исполнение трудовых или иных обязанностей;

5 Об утверждении перечней медицинских услуг и дорогостоящих видов лечения в медицинских организациях, у индивидуальных предпринимателей, осуществляющих медицинскую деятельность, суммы оплаты которых за счет собственных средств налогоплательщика учитываются при определении суммы социального налогового вычета: Постановление Правительства РФ от 08.04.2020 г. № 458. Собрание законодательства РФ. 2020. № 15 (часть IV). Ст. 2309. суммы, полученные от профсоюзных организаций, выплачиваемые их членам, за добросовестное и активное участие в деятельности профсоюзной организации, а также в связи с государственными праздниками и юбилейными датами физических и юридических лиц;

доходы, полученные физическими лицами-инвесторами от участия в инвестиционных фондах, при условии, что они зарегистрированы в Республике Беларусь до 2025 г.;

премия, полученная участником государственной системы жилищных строительных сбережений;

доходы выпускников, получивших образование на очной форме обучения, полученные от сдачи внаем жилых помещений;

доходы в виде возврата денежных средств, внесенных в оплату цены одноквартирного жилого дома или квартиры при их приобретении по договору долевого строительства с последующим оформлением договора купли-продажи, предусматривающего оплату цены этого жилья в рассрочку;

проценты, начисляемые за период размещения семейного капитала в банковские вклады физических лиц.

Кроме стимулирующих мер, белорусский законодатель также предусматривает и противоположные меры:

в период 2021-2023 гг. в отношении доходов, полученных по трудовым договорам от резидентов различных инвестиционных проектов (Парка высоких технологий, Китайско-белорусского индустриального парка «Великий камень»), увеличивается ставка подоходного налога с 9 до 13\%;

повышены ставки подоходного налога с физических лиц в отношении доходов, полученных от сдачи в аренду, наем жилых и нежилых помещений, а также машино-мест ${ }^{6}$.

6 Об изменении Налогового кодекса Республики Беларусь: Закон Республики Беларусь от 29 декабря 2020 года №72-3. URL: https://pravo.by/document/?guid= $12551 \& \mathrm{p} 0=\mathrm{H} 12000072 \& \mathrm{p} 1=1 \& \mathrm{p} 5=0 ;$ Налоговый Кодекс Республики Беларусь (Особенная часть): Кодекс Республики Беларусь от 29.12.2009 г. № 71-3. URL: http:// www.nalog.gov.by/ru/TAX CODE RU/view/r-kodeks-

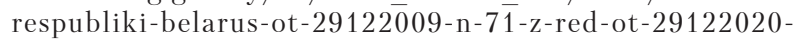
nalogovyj-kodeks-respubliki-belarus-38429/ 


\begin{tabular}{lllll}
\hline \hline & $*$ & $*$ & $*$
\end{tabular}

Рассматривая меры стимулирования и принуждения в теории и практике современного налогообложения, следует отметить, что нельзя говорить о необходимости преобладания одного или другого направления, поскольку для эффективной налоговой политики важен баланс этих двух направлений. Несмотря на проблемы в экономике в связи с пандемией, увеличившийся дефицит бюджета, государства не стали принимать налогово-правовые нормы, только усиливающие налоговое бремя для налогоплательщиков. Параллельно были рассмотрены налоговые льготы, необходимые для их поддержки в современных сложных условиях.

Подводя итоги вышеизложенному, можно прийти к следующим выводам:

налоговая политика любого государства базируется на балансе частных и публичных интересов, совмещает меры принуждения и поощрения налогообложения. В связи с этим предлагается принципы налогообложения дополнить принципом баланса налогового принуждения и поощрения с возможностью его закрепления в налоговом законодательстве, что послужит дальнейшему развитию теории и практики налогообложения;

кризисные явления в экономике актуализируют проблему, связанную с применением стимулирующих мер, поскольку в условиях дефицита бюджета они не являются экономически целесообразными, однако их наличие помогает оказывать поддержку хозяйствующим субъектам в условиях экономической нестабильности;

в сложившейся практике современного налогообложения наблюдается тенденция к прогрессивному налогообложению, особенно в России. В связи с этим хотелось бы, чтобы в кризисных условиях экономики инициатива повышения ставки НДФЛ для лиц с высоким доходом исходила от налогоплательщиков, имеющих доход более 10 млн руб. в год. Для этого государству следует предусмотреть меры, стимулирующие их к подобному поведению. Альтернативным способом будут меры принуждения в виде правовых норм, закреп- ленных в налоговом законодательстве по инициативе государства;

практика применения налогового законодательства и России, и Беларуси указывает на использование мер стимулирования подоходного налогообложения физических лиц с целью формирования правомерного поведения налогоплательщика и оказания налоговых мер финансовой поддержки в условиях экономического кризиса, вызванного пандемией. Целесообразно в этой связи, по крайней мере для России, введение минимальной необлагаемой НДФЛ суммы дохода в месяц по опыту зарубежных стран, позволяющей поддержать лиц с низким уровнем доходов.

\section{СПИСОК ЛИТЕРАТУРЫ (REFERENCES)}

Белякова Е.И., Моденов А.К. 2019. Налоговое стимулирование как инструмент реализации налоговой политики. Петербургский экономический журнал. № 2. C. 134-143. [Belyakova E.I., Modenov A.K. 2019. Tax incentives as a tool for tax policy implementation. Peterburgskiy ekonomicheskiy zhumal. No 2. PP. 134-143. (In Russ.)]

Быков С.С. 2014. К дискуссии о понятии противодействия уклонению от уплаты налогов и его значении в признании налогового права самостоятельной отраслью. Известия Иркутской государственной экономической академии. № 1. С. 90-99. [Bykov S.S. 2014. To discussion on the notion of counteraction against tax evasion and tax avoidance and their value in recognition of tax law as an independent branch. Izvestiya Irkutskoy gosudarstvennoy ekonomicheskoy akademii. No 1. PP. 90-99. (In Russ.)]

Карасева М.В. 2003. Бюджетное и налоговое право России: политический аспект. Москва: Юристъ. 176 с. [Karaseva M.V. 2003. Budget and Tax Law of Russia: A political aspect. Moscow: Yurist. 176 p. (In Russ.)]

Клюев Ю.В. 2020. Прогрессивная шкала НДФЛ в России и ее социальная направленность. Финансовые рынки и банки. № 5. С. 45-47. [Kliuev Yu.V. 2020. Progressive scale of personal income tax in Russia and its social orientation. Finansovye rynki $i$ banki. No 5. PP. 45-47. (In Russ.)]

Князева О.Н., Шагланов А.Н. 2014. Специфика налогового принуждения в Российской Федерации. Инфраструктурные отрасли экономики: проблемы и перспективы развития. № 6. C. 102-106. [Knyazeva O.N., Shaglanov A.N. 2014. Specifics of tax enforcement in the Russian 
Federation. Infrastrukturnye otrasli ekonomiki: problemy $i$ perspektivy razvitiya. No 6. PP. 102106. (In Russ.)]

Кобзарь-Фролова М.Н. 2010. Проблемы правового регулирования предупреждения налоговой деликтности. Бизнес в законе. № 1. С. 5862. [Kobzar'-Frolova M.N. 2010. Problems of legal regulation of prevention of tax tort. Biznes $v$ zakone. No 1. PP. 58-62. (In Russ.)]

Митрофанова И.А. 2013. Экономическая сущность, принципы, функции налога на прибыль: эволюционный подход. Финансы и кредит. № 44. C. 39-51. [Mitrofanova I.A. 2013. The economic essence, principles, and functions of the income tax: an evolutionary approach. Finansy $i$ kredit. No 44. PP. 39-51. (In Russ.)]

Сокул П. 2010. Налоги и их функции в современной экономике. Вестник Ярославского государственного университета им. П.Г. Демидова. Серия гуманитарные науки. № 1. С. 115-122. [Sokul P. 2010. Taxes and their functions in modern economy. Vestnik Yaroslavskogo gosudarstvennogo universiteta im. P.G. Demidova. Seriya gumanitarnye nauki. No 1. PP. 115-122. (In Russ.)]

Сунцева П.В. 2010. Злоупотребления налоговых органов и злоупотребления налогоплательщиков в публичном праве. Вестник Пермского университета. Юридические науки. № 3. С. 8594. [Suntseva P.V. 2010. Abuse of rights admitted by rating authorities and abuse of rights admitted by taxpayers in public law. Vestnik Permskogo universiteta. Yuridicheskie nauki. No 3. PP. 85-94. (In Russ.)]

Madison A. 2016. The Legal Consequences of Noncompliance with Federal Tax Laws. Tax Lazyer. Vol. 70. No 1. PP. 367-402.

In citation: Belorusskiy Ekonomicheskiy zhurnal. 2021. No 2. PP. 63-69.

Belarusian Economic Journal. 2021. No 2. PP. 63-69.

\title{
PERSONAL INCOME TAXATION: TENDENCIES FOR COERCION AND INCENTIVES
}

\author{
Yulia Tsaregradskaya ${ }^{1}$ \\ Author affiliation: ${ }^{1}$ Moscow State Institute of International Relations (Moscow, Russia). \\ Corresponding author: Yulia Tsaregradskaya (ukmsal@mail.ru). \\ ABSTRACT. The article studies personal income taxation given the functions performed by the taxes. \\ The study concluded that while collecting taxes government turns to both coercion and incentives and view \\ them interdependent.
}

KEYWORDS: income tax, the Republic of Belarus, Russia, incentives, coercion.

JEL-code: H24, K34.

DOI: $10.46782 / 1818-4510-2021-2-63-69$

Received 19.04.2021 